Scientia studia, São Paulo, v. 4, n. 3, p. 485-508, 2006

\title{
st \\ Caminhos do conhecimento comercial: formas e conseqüências da sinergia universidade-empresa nas incubadoras tecnológicas
}

\author{
Terry Shinn \& Erwan Lamy
}

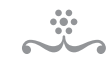

RESUMO

Este artigo examina os caminhos da aprendizagem comercial, em um ambiente que é visto como multirreferencial e pluralista. A categoria dos cientistas-empreendedores, ricamente informativa, constitui nosso terreno de pesquisa. Tal grupo representa o ápice de uma forte interação entre a ciência e a empresa. Dados de um questionário escrito e entrevistas orais extensivas com 411 pessoas, oriundos de quatro microestudos sobre laboratórios-empresa constituem a base de nossa descrição e de nossas conclusões. Emergem três caminhos para o conhecimento comercial - um associado ao grupo denominado "acadêmicos", outro associado a um conjunto apelidado de "pioneiros" e um terceiro ligado a um grupo batizado de "janus". Esses grupos divergem com referência a quatro fatores: graus de sinergia universidadeempresa, graus de tensão universidade-negócio; graus de autonomia relativa do campo científico; presença de um modo particular de coordenação universidade-empresa. Especulamos que certos caminhos se mostram mais estáveis e efetivos do que outros na geração e difusão do conhecimento comercial. Nossa descoberta de múltiplos caminhos dentro do processo de conhecimento comercial, ocorrendo num ambiente multirreferencial e pluralístico, desafia a mensagem da contextualização radical da ciência no modo 2, que propõe uma significativa diminuição das fronteiras entre a ciência, a indústria e a sociedade, ou mesmo a aniquilação das ditas fronteiras e diferenciações.

Palavras- $\mathrm{chaVe} \bullet$ Conhecimento comercial. Multirreferência. Ambiente pluralístico.

Sinergia universidade-empresa. Índice de sinergia. Autonomia relativa. Modos de coordenação.

Cruzamento de fronteiras.

\section{INTRODUÇÃO}

Impulsionadas por políticas governamentais, por mudanças nas circunstâncias econômicas, por editais de empresas, por processos de globalização, e não menos por toda expediência política e mudança de ideologia, muitas das relações entre a academia e os negócios, e entre a pesquisa básica e as aplicações tecnológicas, mudaram no decurso do último quarto de século, muitas vezes de forma dramática em algumas disciplinas e 
setores econômicos mais do que em outros, por exemplo nas ciências médicas, nas ciências dos materiais e na informática. A transformação nas interações entre a academia e a empresa é bem documentada em termos de: co-publicação entre funcionários de universidades e companhias, crescente quantidade de patentes solicitadas por pesquisas acadêmicas e universitárias, pesquisa e desenvolvimento (P\&D), licença ou venda de direitos, assistência técnica, várias cooperações formais e informais e contratação de profissionais capacitados etc. Hoje em dia esses caminhos constituem a maioria dos influxos entre universidade/empresa (Reamer et al., 2003). Pode-se observar aqui a expansão dos números e novas formas de interpenetração contratual e organizacional, agora disponíveis aos dirigentes das universidades e das firmas. Tais arranjos têm estimulado e facilitado iniciativas de um corpo crescente de pesquisadores acadêmicos, engajados em pesquisa fundamental, no sentido de dar um passo a mais na direção de montar seus próprios empreendimentos, enquanto mantêm simultaneamente suas posições acadêmicas. A realidade do movimento dos cientistas acadêmicos na direção do conhecimento comercial é, portanto, hoje irrefutável (Etzkowitz \& Leydesdorff, 2000; Godin \& Gingras, 2000; Krimsky, 2003; Lamy, 2005; Nowotny et al., 2001; OwenSmith, 2003; Slaughter \& Leslie, 1997; STI Review, 2001).

A abundante documentação da evolução favorável ao conhecimento comercial, não obstante, não responde a duas perguntas cruciais (e gêmeas): o que é que tal transformação especificamente implica para a relativa mudança de posição dos indivíduos, não mais solidamente situados dentro da academia, mas operando num ambiente multirreferencial e pluralista; e o que isso implica para a composição resultante, equilíbrio e gerenciamento da cognição empregada. Para explorar a dinâmica interna e os perfis resultantes dos cientistas que geram e aplicam o conhecimento comercial, selecionamos informação estratégica a respeito da população de cientistas que fundaram suas próprias empresas e têm ativamente participado nelas. Este trabalho relata os resultados de um estudo de quatro anos com 41 indivíduos e a respectiva microanálise de quatro empresas. A pesquisa põe o foco na França do período de 1990 a 2003. A população da amostragem está ligada ao Centre National de la Recherche Scientifique (CNRS) e às universidades; e é constituída por aqueles que, em virtude do estabelecimento de uma firma ao mesmo tempo em que mantêm suas posições acadêmicas, tornaram-se conhecidos como "pesquisadores-empreendedores" ou "pesquisadores criadores de empresa". Este estudo explora como os cientistas envolvidos na produção e aplicação do conhecimento comercial percebem a conjunção entre a academia e os negócios, e como eles enfrentam as questões da interface entre a academia e os negócios.

O trabalho estabelece três perfis ligados aos processos de conhecimento comercial, cada qual exibindo seu modo específico de coordenação academia-empresa. O grupo chamado de "acadêmicos" exibe um modo estratégico (um aparelhamento da 
empresa em função de interesses científicos). Outra categoria batizada de "pioneiros" desenvolve um modo imitativo de coordenação (a adaptação do cientista aos objetivos empresariais). Um terceiro grupo apelidado de "janus" manifesta um modo de coordenação "seqüencial" (alternando passagens entre a academia e a empresa). Cada um desses modos de coordenação acompanha formas diferentes de sinergia entre universidade-empresa e são caracterizados por diferentes níveis de “tensão" entre universidade-empresa.

Os resultados empíricos apresentados a seguir questionam o argumento da extrema "contextualização da ciência" de Gibbons e Nowotny que insistem que as fronteiras da ciência hoje se encontram substancialmente diminuídas, quando não erradicadas (Cf. Gibbons et al., 1994; Gibbons et al., 2001). A hipótese deles propõe que o aumento da efetividade tecnológica, a performance da economia e a melhoria da sociedade são contingentes a um sistema de conhecimento essencialmente estruturado em formas de aprendizagem comercial, o que necessita a atrofia das fronteiras da universidade e da ciência, para o benefício das empresas e demais instâncias. Entretanto, nossa evidência empírica detalhada aponta numa direção diferente. Indica que mesmo dentro do panorama de aceleração do conhecimento comercial, continuam a existir fronteiras entre a ciência e a empresa. Os grupos denominados janus e acadêmicos sustentam essas fronteiras, e os pioneiros relutantemente as toleram ou voluntariamente as aceitam. Aparentemente, os supostos efeitos perniciosos da manutenção das fronteiras são suficientemente mitigados por mecanismos dos vários modos de coordenação já mencionados. Parece haver uma ainda não totalmente explicada e altamente complexa correlação positiva entre o grau de sinergia e o grau de autonomia acadêmica. Neste estudo, "sinergia" se refere a benefícios recíprocos advindos das diferentes unidades organizacionais através de interações mútuas, por exemplo entre as pequenas e médias indústrias e as instituições de pesquisa acadêmica (Fiset et al., 1999). O conceito sociológico de autonomia ora adotado chama atenção para as estratégias das organizações, para a operação e o posicionamento relativo na base de um sistema regulatório interno, incluindo metas, recompensas, capacidade de afiliação e outros mecanismos auto-referentes de seleção (Merton, 1973 [194,2]; Freidson, 1994, 2001). Onde a autonomia científica se mostra bastante alta, nota-se que a sinergia entre os laboratórios públicos e a empresa é igualmente elevada. Adicionalmente, sugere-se que certas categorias de cientistas-empreendedores demonstram maior facilidade do que outras no tocante ao gerenciamento de um ambiente multirreferencial e pluralista, tal como acontece na geração e na aplicação do conhecimento comercial. 


\section{Contexto E AdVERTÊncia}

As iniciativas do governo francês para pressionar a universidade e as agências públicas nacionais de pesquisa, tal como o prestigioso CNRS, no sentido de uma aproximação com a indústria e de colaborações favoráveis com a iniciativa privada datam do início dos anos 80 (cf. Vavakova, 2001). Uma legislação, proposta em 15 de julho de 1982, estabeleceu uma nova categoria de laboratório misto entre o setor público do CNRS e a iniciativa privada, introduziu uma dose de descentralização administrativa projetada para estimular uma maior interação entre a pesquisa pública e as empresas, forneceu medidas específicas para possibilitar a mobilidade entre o pessoal do setor público e a indústria, e colocou a obtenção de patentes e o envolvimento com a indústria como critérios de avaliação no recrutamento e promoção de pessoal envolvido em pesquisa. Desde a adoção dessas medidas e de sua implementação parcial, o número de contratos de laboratórios de pesquisa mistos CNRS/empresa aumentou significativamente, demonstrando maior interação entre os setores públicos e privados de pesquisa. Os números desses contratos giraram em torno de 1100 em 1986, 1077 em 1995 e 1386 em 2003 (cf. Vavakova, 2001, p. 245; GNRS, 2005). Embora parte desse aumento certamente provenha do envolvimento de um número maior de cientistas em projetos relacionados à indústria, uma proporção significativa provém de uma multiplicação do número de contratos por pessoa. O número total de contratos excede de longe o número de cientistas contratados, pois os pesquisadores comprometidos com a indústria tendem a acumular projetos empresariais (cf. Grossetti, 1995). Essa mudança pode ser interpretada como um fortalecimento moderado do envolvimento geral do CNRS em empreendimentos, correlacionado com um importante fortalecimento da participação de um pequeno mas vigoroso grupo dentro da agência. Alegitimidade resultante da orientação e do trabalho dos projetos empresariais no CNRS abriu espaço para o entrincheiramento de uma nova sub-comunidade dentro da agência nacional. Com o tempo, uma nova divisão da ciência estabelecida pelo GNRS - ciência para engenheiros - posta em pauta em meados da década de 70 (cf. Ramunni, 1995), tornou-se o cerne dos contratos CNRS-indústria e o foco do processo de produção de conhecimento comercial.

Na medida em que a inovação tornou-se central para a vida política e industrial e para a ideologia na França, as políticas públicas e a legislação aumentaram a pressão sobre os cientistas no sentido de estabelecer conexões com a indústria e/ou a fundação de suas próprias indústrias de base tecnológica. A inovação emergiu como o foco do discurso político e industrial, no qual era vista como uma panacéia para o desemprego, um atalho para o crescimento econômico e para a prosperidade e um emblema de sinergia, de sucesso e de resultados. Os cientistas, e talvez mais ainda os do GNRS do que os de outros grupos, foram instados a tornarem-se pioneiros da inovação através do 
estabelecimento de suas próprias firmas, daí por diante tornando-se "pesquisadoresempreendedores" ou, para usar uma designação alternativa "pesquisadores criadores de empreendimentos" (cf. Mustar, 2003). A legislação em 1999 e 2003 facilitou significativamente a mobilidade e a participação direta na indústria. A agência introduziu três artigos regulatórios para os cientistas interessados em formas estáveis e diretas de envolvimento industrial: o artigo $25^{-1}$ permite aos cientistas do setor público estabelecer firmas com o propósito de desenvolver projetos comerciais a partir de trabalhos de laboratório; o artigo $25^{-2}$ permite consultorias de longa duração em firmas privadas relacionadas com o desenvolvimento da pesquisa acadêmica; o artigo 25-3 dá aos cientistas do setor público o direito de se tornarem membros oficiais da diretoria de companhias privadas. ${ }^{1}$ Além disso, por vezes o CNRS prometia aumento da verba de laboratório ao pessoal que fundasse uma firma. Houve recrutamento específico de pessoas dispostas a dividir seu tempo entre a jornada acadêmica e a nova empreitada particularmente promissora.

Essas medidas aplainaram o que havia sido anteriormente um trajeto sinuoso entre a indústria e os pesquisadores com aspirações empresariais. Negócios industriais de curta duração ou improvisados, enquanto relativamente intermitentes, constituíam um mecanismo satisfatório para o pessoal do GNRS, contentes que estavam com a frouxa ligação com a indústria, não obstante acontecesse aos cientistas plenamente comprometidos com a participação em empresas às vezes terem que agir fora das normas e regulamentações do CNRS em seus assuntos empresariais particulares (freqüentemente protegidos pela vista grossa da administração do GNRS). E, mais, regulamentações coorporativas eram barreiras suficientes para limitar ou bloquear a criação de novas iniciativas. As alterações nos artigos regulatórios coincidiram com o aumento no número de cientistas vinculados ao GNRS que estabeleceram suas próprias companhias ou optaram por formas de envolvimento entre o laboratório e as empresas (cf. Mustar, 2001). Embora a base de dados do CNRS não seja sistemática e às vezes até seja incompleta, ainda é evidente que durante os últimos 15 anos o número de firmas novas têm crescido. Entre os anos de 1990 a 1995, o número médio anual foi de 15 aberturas. Entre 1996 e 2000, a média anual cresceu chegando a 21 (cf. Lamy, 2005). No total, de 1990 a 2000 foram abertas 205 firmas. Entre 1999 e 2003 houve um claro aumento nesse número. O CNRS aponta que 149 companhias foram fundadas. Nos anos anteriores, entretanto, tinha havido um ligeiro declínio. O rápido aumento subseqüente provavelmente corresponde a uma cautelosa espera dos interessados pelas novas regulamentações, pois eles anteciparam e aguardaram as mudanças para só então abrirem suas firmas. $\mathrm{O}$ mais significativo para nosso estudo é que, depois de 1999, os cientistas do CNRS optaram 
por regimes mais próximos ao ambiente acadêmico do que ao empresarial - isto é, escolheram o artigo $25^{-2}$, dentre os três artigos já mencionados concebidos para os cientistas do setor público interessados em programas empresariais. Finalmente, merece destaque que, entre as companhias fundadas por cientistas do CNRS entre 1990 e 2003, uma porcentagem desproporcionalmente alta delas se situa em biotecnologia, comunicação/eletrônica e ciências dos materiais - com predomínio da biotecnologia.

Duas advertências fazem-se necessárias. Primeira, embora o número de firmas de pesquisadores-empreendedores tenha multiplicado ao longo dos últimos 15 anos, quando se compara isso com as aspirações e expectativas políticas e econômicas do setor público, a magnitude do aumento e o total dos números devem ser considerados como relativamente modestos. Segunda, em face do fato de que o pessoal científico do CNRS soma 12.000 pessoas ao longo do período, a criação de 300 companhias pode ser considerada surpreendentemente pequena. O aumento do compromisso do pessoal do CNRS com a indústria e a emergência de uma comunidade de cientistas-empreendedores são bastante significativos pois possibilitam a introdução de uma trajetória profissional e cognitiva e apontam um caminho para um futuro desenvolvimento maciço. Mas enquanto escrevemos este artigo, a magnitude do fenômeno dos cientistasempreendedores continua admitidamente circunscrita. Embora haja diversos meios alternativos de transferência universidade-empresa, assim como formas alternativas de intercurso entre os cientistas e a indústria, os parcos números de interação forte e plena dos cientistas do CNRS, aqui documentados, sugerem prudência frente às afirmações acerca de uma bem estabelecida participação direta e incondicional dos cientistas no que diz respeito ao envolvimento com o conhecimento comercial.

\section{Acadêmicos - o modo de GoordenaÇão estratégico}

Henry Etzkowitz (Etzkowitz et al., 2000) sugeriu que, para os cientistas acadêmicos, a demarcação mertoniana e a separação entre a academia e a empresa poderiam ser tão grandes a ponto de fazer com que o envolvimento na empresa fosse estruturalmente impossível. Entretanto, será que operar dentro do panorama mertoniano necessariamente impede alguma forma de entrada no conhecimento comercial? Na verdade, de nossa população de 41 cientistas-empreendedores, 14 pessoas identificaram-se fortemente com a universidade e a pesquisa básica e somente muito levemente com a tecnologia e a indústria, o que, entretanto, não impediu que constituíssem suas próprias firmas. A distância entre o empreendimento e a universidade, desposada ou implicada pela sociologia mertoniana da ciência (Merton, 1973 [194,2]; Kornhauser, 1962; Ziman, 1978), diminuiu tão logo alguns cientistas viram as firmas como instrumentos de reforço 
dos esforços acadêmicos. O investimento em sua firma, feito pelo cientista-empreendedor acadêmico, é proporcional à adequação de seus interesses intelectuais e acadêmicos. Sob essa perspectiva, fica evidente que essa categoria de cientista-empreendedor deve participar em alguma medida no desenvolvimento da aprendizagem comercial ao mesmo tempo em que mantém um compromisso essencial com a universidade. Ora, a forma de demarcação mertoniana não impede o envolvimento na comercialização. Qual é então o posicionamento dos empreendedores frente à empresa, à universidade e à interface entre elas? Que estratégia é adotada por essa categoria de cientistas-empreendedores acadêmicos para coordenar suas ações entre esses dois referenciais?

Cientistas-empreendedores acadêmicos privilegiam o valor científico de suas realizações mais do que o valor econômico. Duas atitudes prevalecem: ou as considerações econômicas são subjugadas por preocupações científicas, ou as questões econômicas são totalmente negadas. Em ambas, a academia é dominante e a empresa é totalmente subserviente. Para o primeiro grupo, a significância de qualquer projeto econômico é determinada pelo mérito científico do resultado da pesquisa. Um de nossos entrevistados declarou: "se um achado é cientificamente insignificante, então não pode ter utilidade para uma empresa". Outra pessoa afirmou que "um resultado científico deve ter mérito científico. A indústria só pode absorver boa ciência”. O segundo grupo simplesmente não tem a percepção da perspectiva econômica. Um entrevistado nos disse que "o objetivo do estabelecimento de uma empresa era puramente científico. Não havia um objetivo econômico!"

Essa percepção restritiva da firma coincide com a existência de uma significativa escala de sinergia científica e profissional entre os referenciais dos negócios e da universidade. Com relação aos benefícios cognitivos da criação de uma firma, dois terços dos acadêmicos entrevistados indicaram ter obtido vantagens substanciais. Uma pessoa disse que: "meu trabalho na indústria abriu novas perspectivas que nunca teriam aparecido no laboratório". Uma segunda afirmou que "a firma tem se mostrado altamente estimulante. É bastante útil possuir interlocutores na indústria." Quase todos os entrevistados indicaram que o laboratório melhorou materialmente em razão da firma. Mas a questão não é exatamente monetária. As vantagens cognitivas relacionadas ao material recaem, sobretudo, no potencial que o laboratório tem para obter, através da firma, novas substâncias que não estariam disponíveis de outro modo, testar em larga escala materiais ou protocolos gerados no laboratório, validar métodos, resultados e materiais em variados ambientes não-laboratoriais; ou encontrar uma variedade pouco usual de questões técnicas ou de pessoal. Na mesma direção, mão-de-obra qualificada, especializada e capitais vindos da firma constituem recursos para a aquisição crucial de instrumentação. O capital vindo das companhias é rotineiramente alocado na manutenção dos equipamentos. 
Similarmente, o reconhecimento profissional e a carreira se beneficiam. Para alguns acadêmicos, o envolvimento na firma aumenta o círculo de contatos e reforça a reputação. Um cientista-empreendedor acadêmico relatou que sua fama cresceu graças a um instrumento desenvolvido para sua firma. O instrumento divulgou seu nome em grupos que nunca seriam alcançados através de sua pesquisa básica. Outros entrevistados sugerem que a ausência da empresa acabaria resultando na erosão de suas reputações. Muitos acadêmicos relatam que as trajetórias de suas carreiras foram beneficiadas pela criação de uma companhia. Um entrevistado afirmou que, ao premiá-lo com a muito respeitada medalha de prata do CNRS, a agência especificamente mencionou a importância de ele haver aberto uma empresa. Outro respondeu que sua promoção no CNRS foi conseqüência direta da criação de um negócio. Em face desse grau de sinergia, poder-se-ia antecipar um impacto positivo sobre a produtividade medida em termos de números de publicações. Aqui, entretanto, a situação é complexa. Um pequeno número de cientistas-empreendedores relata um leve aumento nas publicações durante o período de criação da firma, ou logo após isso. Todavia, um grupo só um pouco menor experimentou uma queda nas publicações. A maioria relata que a produção ficou estável. Não obstante, todos concordaram que a pesquisa fundamental prevaleceu sobre a aplicada. Embora ocorresse um pequeno aumento na pesquisa aplicada logo após a fundação da empresa, essa quantidade caiu dentro de três anos, e a proporção de trabalhos em pesquisa fundamental de fato aumentou. Em resumo, para essa categoria, o estabelecimento de uma companhia não penalizou a pesquisa fundamental e as publicações.

Os acadêmicos estão apenas moderadamente sujeitos a tensões entre universidade-empresa. Nesse caso, não há incompatibilidade intrínseca entre o laboratório universitário e a pesquisa básica, de um lado, e o envolvimento num empreendimento, de outro lado. O elevado índice de autonomia acadêmica relativa (cf. Bourdieu, 2001; Shinn \& Ragouet, 2005), apresentado por essa categoria, não diminui em razão da operação sinérgica entre universidade-empresa; na realidade, o contrário pode bem ser verdade. Uma interação sistemática do cientista-empreendedor acadêmico com a firma funciona como proteção e preserva a fronteira entre a universidade e a firma por meio da injeção de uma via de cruzamento entre esses campos. Um grau de penetrabilidade na fronteira, destarte uma elasticidade do sistema, pode na verdade ser constitutivo de uma autonomia relativa do campo científico (cf. Bourdieu, 2001). Mais do que uma usurpação da autonomia do laboratório, nessa configuração, a dinâmica da sinergia universidade-empresa fortalece a autonomia universitária.

A empresa é um veículo para acessar formas incrementais, ou mesmo novas, de recursos, para aumentar a audiência e para consolidar a legitimidade. O modo de coordenação entre universidade-empresa é estratégico, onde a estratégia consiste em in- 
ventar formas de ação e argumentos que instrumentalizem a empresa a alcançar fins cognitivos disciplinares, freqüentemente explícitos e longamente institucionalizados. Note-se que a empresa serve a esse objetivo, ao invés de interferir nisso, ainda que um resultado não intencional seja a geração e comunicação de conhecimento comercial.

Para ilustrar o caminho comercial do cientista acadêmico, tomemos a carreira de Y. Em 1993, Y e o professor W fundaram juntos a firma Newmat, com o intuito de garantir capital, materiais e instrumentos para o laboratório de Y. No início dos anos 70 , Y havia feito seu doutoramento em física e começado a trabalhar em um grande laboratório multinacional de pesquisa industrial, onde obteve duas patentes antes de deixar o emprego e abandonar o ambiente dos negócios, voltando a ele somente ao fundar sua própria empresa. Y imediatamente obteve uma posição na Grand École de W. Durante a década de 1980 e começo de 1990, ele dedicou-se à pesquisa fundamental em física, publicando mais de 4,0 artigos em periódicos científicos de primeira linha tais como Journal of Chemical Physics, Physica C ou Physical Review B, vários dos quais receberam mais de 100 citações. Em 1993, a pesquisa de Y sobre física dos materiais o levou a uma descoberta na área de termo-elasticidade, cheia de aplicações comerciais: tais resultados foram de imediato publicados na prestigiosa Nature. Depois de obter duas patentes relacionadas, e encorajado pelo professor W, Y fundou a Newmat. O objetivo de $\mathrm{Y}$ era assegurar equipamento e programas de computador necessários para levar a pesquisa acadêmica a um domínio especializado que vinha sendo negligenciado pelo CNRS. As atividades de Y se deram em três fases:

(1) De 1993 a 1995, facilitado por fundos e recursos de pessoal oriundos da Newmat, a continuidade da experimentação em física experimental constituiu o cerne dos esforços de Y, cujo objetivo era identificar, caracterizar e medir as propriedades físicas de um novo material. Nesse ínterim, a produção industrial não estava em pauta, o único objetivo era purificar, estabilizar e padronizar a substância. A existência de uma firma também serviu para agregar legitimidade à pesquisa de $\mathrm{Y}$, que começara a gerar impaciência entre os colegas da academia devido à dificuldade de reprodução de materiais estáveis.

(2) Entre 1996 e 1997, com a assistência do professor W, a Newmat construiu um laboratório próprio independente, projetado para manufaturar o novo material numa base comercial. Y e W, o último tendo acesso a abundante capital de risco, equiparam o local da Newmat com equipamento avançado e mão-de-obra orientada no sentido industrial. Entretanto, a companhia fracassou na produção da tão promissora substância. Apenas uma pequena porção dos recursos ia para o laboratório universitário de Y, mas isso ainda assim foi considerável e essencial para o trabalho dele, cada vez mais questionado. Uma rusga logo se desenvolveu entre a unidade da Grand École de Y e a companhia, de modo que a comunicação se interrompeu. Y foi ademais atingido pelas 
crescentes dúvidas de alguns colegas, e a relutância foi reforçada pelo fracasso comercial da companhia.

(3) Os anos de 1998-2003 testemunharam a re-capitalização da Newmat. O capital novo veio de dois colegas de $\mathrm{Y}$, mais um terceiro investidor do mercado financeiro. Depois de re-capitalizada, a Newmat e Y deixaram de lado a pesquisa fracassada de 1993. Isso significou o fim de um ciclo inicial, e eles passaram a trabalhar sobre um material de natureza semelhante, para o qual havia um mercado industrial sólido bem identificado. Na re-fundação da Newmat, o objetivo de Y continuava sendo, tal como antes, mobilizar recursos para dar continuidade à sua pesquisa fundamental na universidade e reforçar sua posição no cenário científico. Embora Y tenha progredido bastante, acabou tendo novamente dificuldades na estabilização e padronização da sua substância, o que inviabilizava a transferência para a indústria, sua produção em massa e a integração num produto comercial. O novo projeto foi gradualmente sendo esvaziado na medida em que os recursos foram se exaurindo.

A despeito do colapso anunciado da Newmat, ela serviu aos interesses de Y - a vinda de recursos de fora para sua pesquisa básica em física. Y fundou uma firma, funcionando no mundo dos negócios de maneira a corresponder a suas exigências, e deixou sua pesquisa acadêmica intacta - de fato, nam tanto assim, pois também compartilhou substâncias e idéias com outras indústrias. A Newmat permitiu a aceleração dos esforços. O caso de Y e da Newmat documenta como o modo de coordenação estratégico permite a um cientista-empreendedor acadêmico dirigir um negócio tendo em vista uma pesquisa pura e largamente fundamental num programa universitário. A despeito dessa prioridade científica, uma empresa foi criada, pessoas foram empregadas e participou-se do largo terreno do capitalismo. No mundo das firmas de alta tecnologia, fechar não é raro, e a atividade e a rede de trabalho costumam ser vistas, em si mesmas, como contribuições válidas e dignas de mérito.

As motivações dos cientistas-empreendedores se encontram fora do escopo deste estudo, o qual foca os perfis intelectuais e organizacionais deles. Só podemos então especular a respeito das considerações específicas que induzem os acadêmicos a seguir esse caminho. As políticas de pesquisa englobam um elemento geral de fundo. Um declínio dos recursos de capital e de material em virtude dessas políticas é um elemento recorrente no discurso dos acadêmicos, os quais empregam a firma para expandir e estender os recursos necessários. Políticas de pesquisa recentes têm também aprofundado a visão de que a indústria está cada vez mais científica, o que oferece possibilidades cognitivas e econômicas sérias para a ciência, e os cientistas tornam-se mais abertos à indústria e à sociedade em geral. Embora os cientistas-empreendedores acadêmicos redefinam a empresa de modo a servir à ciência, os indivíduos aqui entrevistados também reforçam que a exposição ao ambiente industrial fornece novos 
estímulos e uma oportunidade de encontrar comunidades autenticamente não visadas que, de outro modo, permaneceriam desconhecidas. Considerações disciplinares podem afetar mais seletivamente a trajetória de cientistas-empreendedores. A física é desproporcionalmente representada no grupo de acadêmicos de nosso estudo. Vários campos da física são tradicionalmente mais identificados com a pesquisa fundamental do que com a indústria e, na França, a física é freqüentemente colocada em contraposição à indústria. Embora a indústria não possa ser rejeitada, ela é, não obstante, vista como uma atividade marginal à física. A identificação com essa representação da física e das relações ciência-indústria pode, em alguma medida, predispor grupos específicos de cientistas-empreendedores a considerar uma trajetória acadêmica de interação com a indústria como algo oposto a outras trajetórias possíveis. Seria esclarecedor determinar se um ambiente intelectual similar ao da física, mas em outros campos de saber (cf. Shinn, 1982; Whitley, 1984), induziria um perfil similar caracterizado pelo relativo distanciamento do envolvimento com a indústria.

\begin{tabular}{lcccc}
\multicolumn{5}{c}{$\begin{array}{c}\text { Quadro } 1 \\
\text { Divisão disciplinar }\end{array}$} \\
& acadêmicos & pioneiros & janus & Total \\
Ciências físicas & 4 & 1 & 0 & 5 \\
Ciências da vida & 5 & 5 & 6 & 16 \\
Ciências químicas & 2 & 3 & 4 & 9 \\
Engenharia & 3 & 8 & 0 & 11 \\
Total & 14 & 17 & 10 & 41
\end{tabular}

\section{Pioneiros - o modo de goordenaÇão imitativo}

O perfil do cientista-empreendedor pioneiro é simetricamente oposto ao perfil acadêmico somente no sentido de que este grupo está fortemente identificado com a iniciativa privada ( 17 indivíduos em nossa amostra). Contrariamente ao que predizem os proponentes do modo 2 de contextualização da ciência, ${ }^{2}$ a sinergia entre a academia

$2 \mathrm{O}$ termo "modo 2" refere-se aqui ao modelo de produção do conhecimento científico, proposto em Gibbons et al. (1994) e Nowotny et al. (2001), segundo o qual a história da ciência é dividida em dois modos-padrão: modo 1 e modo 2. O modo 1 refere-se à ciência tal como praticada no século xix e primeira metade do século xx; o modo 2 refere-se a parte da ciência empreendida a partir da Segunda Guerra Mundial e, mais particularmente, a partir dos anos 1970. Afirma-se que a ciência produzida pelo modo 2 está substituindo a ciência produzida pelo modo 1. A produção científica do modo 1 caracteriza-se pelo cenário acadêmico universitário, pelas disciplinas científicas (pelo respeito às 
e a empresa é baixa, e as tensões são altas, de maneira chocante: digo chocante, pois de acordo com o modo lógico 2, essa categoria deveria especificamente ser a que encarnaria e introduziria aquela muita propalada conversão autonegatória da ciência, pela ciência, a favor da indústria. Os pioneiros não neutralizam e desmontam as fronteiras entre a ciência de um lado e a economia e a sociedade de outro, nem fazem o serviço de integração da universidade com a empresa, embora operem em interfaces valiosas, enérgicas e infindáveis entre tais espaços contíguos. Essa categoria cai fora da universidade, mas o conseqüente distanciamento não é suficiente para debelar certos sintomas de nostalgia. Embora o cientista-empreendedor pioneiro seja claramente ator decisivo na produção do conhecimento comercial, em vista da posição limitada do pioneiro dentro do laboratório universitário, pode-se razoavelmente indagar qual é a forma de conhecimento que circula e se introduz nesse meio.

Embora Etzkowitz (1998), assim como Slaughter e Leslie (1997), em suas respectivas análises, apontem corretamente os benefícios que motivam os novos cientistas-empreendedores, essa forma de conhecimento comercial na realidade se mostra infinitamente mais complexa. $\mathrm{O}$ empreendedorismo científico não se reduz aos ganhos, outrossim implica uma transformação mais indiscriminada das preferências e representações.

Essa categoria de cientista pioneiro aposta na chance de enveredar na terra virgem e prometida dos negócios. Os indivíduos não necessariamente percebem esse movimento como radical ou constitutivo de uma mudança significativa. Experimentase uma espécie de aventura, e as pessoas tomam a si mesmas como verdadeiros pioneiros. Muitos pertencem ao Departamento de Engenharia do CNRS, constituindo a metade desse grupo de pioneiros, mas eles são apenas uma quarta parte de toda a população geral de nosso estudo (Grossetti, 1995; Ramunni, 1995). Essa posição institucional rotineiramente leva-os ao mundo dos negócios. É, portanto, sem reticências que os cientistas-empreendedores pioneiros tentam adotar os traquejos do empreendedorismo. Os pioneiros são muito mais comercialmente informados do que os acadêmicos anteriormente descritos.

fronteiras disciplinares) e departamentos acadêmicos baseados nas disciplinas científicas, por questões de pesquisa moldadas nelas, pela idéia de "verdade", pela estrita observância das avaliações da pesquisa feitas pelos pares etc. Em contraste com o modo 1, a ciência produzida no modo 2 prenuncia a queda da academia e da universidade, o fim das disciplinas e sua substituição por questões derivadas das questões econômicas e sociais, o fim da "teoria" enquanto fim central e sua substituição por soluções práticas para problemas concretos, o desaparecimento de laboratórios e da pesquisa em equipe tal como os conhecemos e sua substituição por grupos fluidos que se decompõem e recompõem à medida que as habilidades são requeridas. O modo 2 anuncia o eclipse e o final da ciência tal como historicamente conhecida. Seus promotores freqüentemente usam a tecnologia, a nanociência e a biotecnologia como exemplares do modo 2. 
Os negócios são o referencial mais presente em seu método de trabalho: prevalecem os imperativos econômicos do mercado, que determinam escolhas de pesquisa e cronograma. Guardar segredos ou registrar patentes são mais do que importantes. Um entrevistado pioneiro disse que guardar segredo constitui um problema num laboratório universitário, mas na empresa isso é a norma. Os pioneiros se dedicam à publicação, mas freqüentemente sobre tópicos associados a inovações.

Em contraste com os cientistas-empreendedores acadêmicos, a fundação de uma firma é motivada por considerações mais econômicas do que científicas. Os pioneiros querem algo mais do que a ciência, algo novo. Eles dizem desejar ir além do que a ciência usualmente faz. A empresa fornece um lugar legítimo, relevante e excitante. Não obstante, uns poucos pioneiros indicaram que a paixão pela ciência não minguou. Um deles declarou que embora estivesse ansioso ao abrir uma firma nova, inteiramente voltada para a economia, ele logo lamentou a diminuição de seu envolvimento com o laboratório universitário e, após dois ou três anos, começou a pensar que "a pesquisa acadêmica também não é tão má assim!". A vocação empresarial não representa necessariamente uma reversão da vocação inicial para a ciência acadêmica. Os pioneiros consideram que ela pode ser ajustada ao envolvimento na empresa. Eles buscam a capitalização por meio da ciência, e isso requer flexibilidade das práticas científicas. Portanto, eles não se percebem, ou se pretendem, como dando as costas à pesquisa fundamental da universidade, a despeito de sua distância cada vez maior em relação ao laboratório. A ciência persiste como pano de fundo, mas não é esquecida ou perdida. Para essa categoria de cientista-empreendedor, não há rejeição ideológica da pesquisa fundamental. Mas isso não quer dizer que não haja ideologia no discurso dos pioneiros: eles estão convictos da necessidade de se adaptar a imperativos mercadológicos. O conseqüente distanciamento do laboratório é o preço a ser pago.

Um entrevistado pioneiro apontou explicitamente o baixo nível de sinergia que aqui se dá entre a firma e o laboratório universitário. Enquanto os cientistas-empreendedores acadêmicos testemunham maciçamente uma forte interação entre a pesquisa fundamental e suas firmas, e também mantém sua produtividade em pesquisa, dois terços do grupo de pioneiros notam, ao contrário, uma significativa redução da produtividade científica. Três fatores entram em jogo:

(1) Em contraste com os acadêmicos, os pioneiros passam menos tempo no laboratório do que faziam antes de criar a firma e correspondentemente passam muito mais tempo dedicando-se aos negócios. Na mesma linha, há uma marcante tendência a reduzir a participação na vida da comunidade científica, tal como em colóquios e seminários.

(2) Diferentemente dos acadêmicos, que continuam na pesquisa básica ou logo retornam a ela, a maioria dos pioneiros opta pela pesquisa aplicada. Um pioneiro afirmou que o pouco que ele publica não aparece mais em periódicos científicos. 
(3) Enquanto os cientistas-empreendedores acadêmicos se beneficiam estrategicamente da criação de uma firma, tendo em vista aumentar o capital para instrumentação, os pioneiros não mencionam a expansão de suas capacidades materiais de pesquisa. A firma não tem intenção de servir à ciência e assim logicamente não tem a intenção de contribuir com publicações.

A falta de empenho na pesquisa básica universitária vivida pelos pioneiros repercute em suas carreiras e reputações. Alguns pioneiros comentaram que a criação de uma firma e seu envolvimento nela foram hostilizados por alguns colegas acadêmicos que questionavam a ética da aventura. Mais da metade dos pioneiros acredita que o envolvimento nas suas firmas não recebeu o reconhecimento que merecia por parte do CNRS, apesar da administração incentivar e apoiar a criação de empresas. Nenhuma promoção, nenhum prêmio; ocasionalmente até desrespeito. Essa ausência de reconhecimento profissional e recompensa pelos esforços empreendedores gera desapontamento e até ressentimento em muitos pioneiros, os quais vêem a si mesmos como vigas-mestra de uma excitante e importante esfera de ação e compromisso. Eles se vêem como partícipes da transição do sistema nacional de inovação francês. Suas visões são coletivas: por exemplo, os pioneiros se preocupam com o futuro de seus alunos de graduação e pós-graduação. Eles atentam para a utilidade da firma no treinamento e geração de emprego. Isso contrasta com o foco altamente individualista dos cientistas-empreendedores acadêmicos, majoritariamente preocupados com seu desenvolvimento intelectual pessoal.

E o que dizer do papel dos ganhos pessoais? Foi muito difícil coletar dados amplos e confiáveis a respeito disso, pois o assunto continua tabu mesmo na cultura francesa contemporânea em mudança. Os pioneiros disseram que embora os ganhos sejam importantes, outras considerações também pesam. A despeito da posição ocupada pela recompensa monetária na hierarquia dos motivos, continua o fato de que o perfil do conhecimento comercial que aqui emerge de nossa exploração é muito mais multidimensional do que se costuma pensar e, na verdade, é repleto de contradições. Embora os cientistas empreendedores pioneiros coloquem conscientemente de lado a medida de relativa autonomia usual ao campo científico (suas normas, expectativas e pré-requisitos) quando adotam condutas empreendedoras, mesmo assim a sinergia universidade-empresa correspondente não cresce, na verdade, ocorre o contrário. $\mathrm{O}$ índice de sinergia despenca junto com o índice de autonomia. $\mathrm{O}$ cientista-empreendedor pioneiro pode perfeitamente ser retratado como um entusiasta do avanço, calcando os pés na terra prometida dos negócios, embora relance olhares à ciência que ficou para trás.

O gerenciamento entre o referencial universitário científico e o referencial empresarial, e o gerenciamento da interface entre eles, se dá através de um modo de coordenação imitativo dos pioneiros. $O$ modo imitativo constitui o fulcro entre a empresa e 
a ciência. Esse modo de coordenação procura levar os pioneiros para perto da empresa, mas paradoxalmente é fonte de tensão aguda. Os pioneiros pretendem adaptar-se ao referencial comercial através da adoção do que eles acham que seja a visão empresarial e financeira da ciência. Mas essa imitação costuma falhar no que tange à satisfação das expectativas dos parceiros comerciais. É essencial entender que a conduta dos pioneiros não é uma prática empresarial estritamente "autêntica”, "pura”. Em razão de sua educação, de sua experiência profissional inicial e de seus hábitos, um pioneiro não é por formação um administrador, um contador, um representante ou um marqueteiro. O pioneiro procura e adota para si, tal como pode, o ethos e os mecanismos dos negócios, mas tais coisas não são de todo assimiladas. Se essa situação embaraça, em alguma medida, sua capacidade empresarial, não obstante há um preço a ser pago para a sustentação da credibilidade dentro do referencial universitário. A assimilação total à perspectiva comercial ameaça fortemente a aceitação do pioneiro pela comunidade acadêmica. $\mathrm{O}$ custo de ser pioneiro portanto é alto, na medida em que o modo de coordenação imitativo enseja uma inesgotável tensão entre a empresa e a academia adversária. A alegada fusão entre o pioneiro e a empresa, e entre a ciência e a iniciativa privada, descrita no modo 2 (Gibbons et al., 1994; Nowotny et al., 2001) realmente não ocorre nesse campo privilegiado a priori.

Finalmente, o que dizer do papel desempenhado pelos cientistas-empreendedores pioneiros na produção e difusão do conhecimento comercial? O termo "conhecimento comercial" é em si mesmo repleto de significados para sociólogos, economistas, cientistas políticos e administradores públicos que dele se utilizam, e a descrição aqui feita dos pioneiros pode até complicar a relevância e a confiabilidade do termo. Aquestão real é a seguinte: que tipo de conhecimento comercial é veiculado pelos pioneiros? Nossa investigação sugere que eles adaptam esse conhecimento ao que eles acham que isso deveria ser, e não exatamente ao que os parceiros industriais esperam. Por conseguinte, os pioneiros talvez representem mais uma fonte potencial e antecipatória de conhecimento do que um canal robusto de aprendizagem comercial. Aqui então aparece uma situação paradoxal: a categoria de cientista-empreendedor que mais fortemente se identifica com os negócios, e que está mais integrada com eles, constitui o grupo que apresenta o menor vetor de importação de aprendizagem favorável aos negócios.

Pode-se conjecturar duas condições estruturais que inclinam certos cientistas na direção da trajetória dos pioneiros. Primeira, como já foi indicado anteriormente, muitos pioneiros estão lotados em escalões médios e inferiores da hierarquia acadêmica. Na França, como em outros países, as oportunidades de carreira encontram-se cada vez mais congestionadas. Mudança e grande ascensão na carreira não são acessíveis a muitos. Isso leva alguns cientistas a procurar carreiras mais satisfatórias fora da universidade. O próprio CNRS na verdade encoraja isso. Ademais, os pioneiros estão 
correlacionados positivamente com alguns nichos disciplinares. As engenharias representam a maior parte desse grupo. A conexão entre as engenharias e as empresas é muito antiga. Mas a distância entre essa comunidade e a indústria tem sido grande, até mesmo estrutural. É possível que essa situação disciplinar específica torne os pioneiros mais sensíveis ao discurso da chamada "aventura capitalista" de criação de uma empresa, que é incessantemente promovida pela imprensa, pelo governo e pelas políticas de ciência, criando a noção de que se trataria de um objetivo válido e virtuoso, por vezes retratado até como um dever do cientista. $O$ espírito de aventura e o comprometimento social, associados à frustração ou à desilusão profissional, são traços que unem os comentários de vários pioneiros em nosso estudo. E é bastante possível que isso, em alguma medida, esteja por detrás da escolha de estabelecer uma firma, aproximarse dos negócios e distanciar-se significativamente da academia.

\section{JANUS - O MODO DE GOORDENAÇÃO SEQÜENGIAL}

Até agora, a discussão sobre os cientistas-empreendedores acadêmicos e pioneiros serviu principalmente para esclarecer detalhadamente certos traços importantes mas freqüentemente superdimensionados a respeito de dois grupos já bem identificados na literatura dos estudos sobre ciência e inovação. Vamos agora explorar uma terceira categoria de cientista-empreendedor que vinha recebendo pouca atenção em estudos anteriores (cf. Cassier, 2002) e que consiste na mais nova e efetiva comunidade produtora de conhecimento comercial. Essa categoria, notavelmente, é a que sofre as menores tensões por parte da empresa e da ciência. Nós a batizamos de "janus" (o nome da divindade romana que olha em direções opostas) porque seus membros divisam duas direções - em certo momento olham a ciência, e em outro voltam-se para a empresa. Diferentemente dos acadêmicos, cujo índice de autonomia é alto e o índice de sinergia é mediano, e também dos pioneiros, cuja autonomia é baixa e a sinergia igualmente, os índices de autonomia e sinergia são ambos altos para o grupo janus. $\mathrm{O}$ modo de coordenação de janus pode ser classificado como seqüencial, significando que eles não se percebem a si mesmos como operando simultaneamente na universidade e nos negócios; outrossim trabalham prioritariamente num ambiente, depois trabalham no outro, de maneira intermitente e seletiva cruzam as fronteiras com um movimento pendular. Um deles disse: "ou se faz ciência ou se faz negócios: é impossível ser cientista e empreendedor ao mesmo tempo!"

Ao contrário dos acadêmicos e pioneiros, que invariavelmente privilegiam um ou outro domínio, o grupo janus recusa-se a dar absoluta prioridade à ciência ou à empresa. A prioridade é dependente do contexto: depende inteiramente de qual das 
duas esferas está sendo ocupada por um janus em determinado momento. Os janus não são menos entusiastas do que os pioneiros no que concerne a questões econômicas, eles são simplesmente mais flexíveis em suas abordagens para o estabelecimento de uma firma e, similarmente, preocupam-se menos do que os acadêmicos a respeito dos benefícios científicos de montar a firma. A seguir transcrevemos citações típicas de um cientista-empreendedor de tipo janus:

\begin{abstract}
"Elas (a ciência e a empresa) são coisas diferentes. Elas não são opostas uma à outra. A ciência não requer justificação econômica. Uma troca ocorre entre a ciência e a empresa. A empresa possui um programa compatível. Não obstante, são esferas separadas e podem funcionar de maneira independente."
\end{abstract}

"Procura-se conciliar as duas. Eu não me posiciono no sentido de separá-las ou opô-las. O envolvimento com os negócios pode ocupar uma fase da vida, mas os negócios não se confundem com a ciência. Há apenas 24, horas em um dia."

Tal como os pioneiros fazem rotineiramente, quatro quintos dos janus estruturam suas agendas de pesquisa em função de questões econômicas em certo ponto de suas carreiras. Como disse um janus, "o motivo industrial é temporariamente prioritário". A dimensão temporal é das mais importantes. Os janus se engajam completamente na empresa quando o referencial empreendedor toma a frente, enquanto para os acadêmicos o contato com o referencial empresarial é consistentemente subjugado ao referencial acadêmico e suplantado por ele. Para os janus, prevalece a divisão do trabalho: há trabalho acadêmico levado em conexão com o referencial acadêmico, e há um trabalho empresarial distinto conduzido dentro do quadro do referencial econômico, conquanto ambos permaneçam conectados e coordenados. Para os acadêmicos, até as atividades executadas dentro do quadro referencial econômico são ajustadas à universidade. E, analogamente, os esforços acadêmicos dos pioneiros predominantemente se ajustam à empresa.

No caso de janus, a ciência e a empresa são ambas autônomas. A autonomia relativa, do tipo da exibida pelo campo científico (cf. Bourdieu, 2001; Joerges \& Shinn, 2001; Lamy, 2005; Shinn \& Ragouet, 2005), não exclui passagens seletivas entre as fronteiras, e isso é o que precisamente caracteriza os cientistas-empreendedores janus. Essas passagens entre fronteiras constituem o mecanismo subjacente do elevado grau de sinergia dessa categoria, na qual a aprendizagem acadêmica serve à empresa assim como a empresa nutre a academia. As configurações de acadêmicos e pioneiros mostram-se efetivamente diferentes de janus, na medida em que nesses grupos a igualdade não caracteriza as interações entre ciência e empresa. Não obstante, as duas desi- 
gualdades não são simétricas: o índice de autonomia dos acadêmicos é alto. Passagens entre as fronteiras ocorrem, mas o fluxo excedente se dirige exclusivamente da empresa para a universidade. Por contraste, os pioneiros não se preocupam com a autonomia do campo científico. Tal como declarara um pioneiro, "a ciência é apenas o meio no qual eu surfo”. Os negócios são o referencial predominante para o pioneiro. Não há necessidade de passagens entre as fronteiras, na medida em que a universidade é apenas o pano de fundo nas operações empresariais, e não um recurso interveniente afirmativo, tal como ocorre inversamente para os acadêmicos. As especificidades de nossas três categorias de cientistas-empreendedores, em termos de autonomia, sinergia e tensão, são representadas no quadro abaixo.

QuADRo 2

Modos DE GOORDENAÇÃo E PERFIS DE GIENTISTAS EMPREENDEDORES

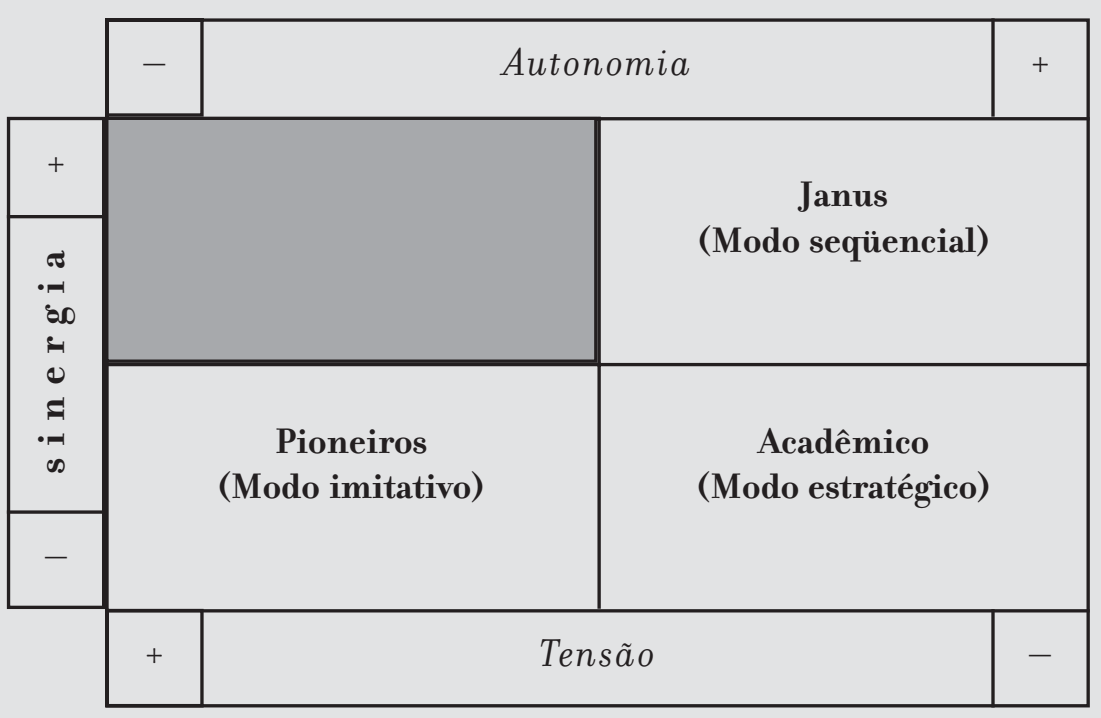

A despeito do forte envolvimento de janus com a empresa, isso não influencia negativamente a produção e a comunicação acadêmica, tal como ocorre com os pioneiros. Pelo contrário, os cientistas janus afirmam que os recursos materiais e a experiência de gerenciamento de pessoal, oriundos da firma, estimulam a publicação e o trabalho em rede. Um deles declarou que a qualidade do controle de protocolos desenvolvido em sua firma expandiu sua fama internacional e mostrou-se útil no trabalho laboratorial. $\mathrm{O}$ crescimento da publicação freqüentemente origina-se de co-publicações entre universidade-empresa, ou diretamente de artigos sobre tecnologia aplica- 
da. Quando ocorre um declínio na pesquisa fundamental, sua duração é curta. Das três categoriais, é a janus que mais se envolve em pesquisa fundamental. Aqui, ciência fundamental não é a antítese da tecnologia industrial, nem é obstáculo a ela. Pelo contrário, a pesquisa fundamental funciona como fonte da criação de uma firma.

Enquanto vários pioneiros reclamam que a criação de uma firma denegriu suas carreiras acadêmicas, essa reclamação é pouco freqüente entre os janus. A diferença na percepção e na análise pode estar no fato de que os dois grupos ocupam posições acadêmicas contrastantes dentro da hierarquia universitária. A maioria dos janus ocupa posições próximas ao topo do CNRS ou dos escalões profissionais universitários. Os pioneiros, ao contrário, tendem a ocupar postos de nível intermediário e, portanto, estão numa posição que os faz entrever ameaças a suas carreiras e ambições. Diferentemente dos acadêmicos, ainda que em paralelo aos pioneiros, os janus têm uma percepção coletiva da ciência e da empresa. Eles efetivamente preocupam-se com seus estudantes. Isso contrasta com o já notado comportamento estratégico e individualista dos cientistas-empreendedores acadêmicos.

O modo de coordenação adotado pelo grupo janus difere de ambos os modos adotados pelos acadêmicos e pioneiros, estratégico e imitativo respectivamente. Não é um modo estratégico porque, diferentemente dos acadêmicos, os janus não estabelecem uma firma tendo em vista reforçar expressamente a pesquisa científica, e dado que já se encontram no topo da hierarquia acadêmica, a firma não tem a intenção de impulsionar aspirações de carreira. Tampouco o modo de coordenação de janus é imitativo, pois diferentemente dos pioneiros, os cientistas janus privilegiam a esfera econômica de maneira apenas seletiva, local ou temporalmente, sem jamais santificá-la com legitimidade. Os janus não optam pelo abandono do mundo científico para perseguir contingências econômicas, mas adaptam-se às situações empresariais antes de voltar à universidade e à ciência. Os janus coordenam períodos de tempo ao invés de coordenar formas de prática. Como indicado por um janus, "o cientista-empreendedor é um mito: uma pessoa é uma coisa ou é outra. Um dia só tem 24 horas." As práticas de janus são verdadeiramente estruturadas em torno da alternância de focos de atenção - algumas vezes sobre a universidade, outras vezes sobre a indústria. Aqui, então, aparece o modo de coordenação seqüencial.

Esse modo de coordenação seqüencial é exemplificado pela carreira do cientista-empreendedor X. Quando da fundação de sua firma em 1994, X não tinha familiaridade com a esfera econômica. X era um químico teórico jovem e brilhante, já possuindo a posição de diretor de pesquisa junto ao CNRS, e seu currículo incluía mais de 60 artigos em periódicos prestigiosos tais como o Journal of Physical Chemistry, Physical Review Letters ou Langmuir, e 12 desses artigos haviam recebido mais de 100 citações. A despeito do sucesso em ciência fundamental, foi com entusiasmo que ele criou uma 
firma, a Biochem, percebendo que uma de suas descobertas prometia resultados industriais na interface da biologia com a química. Durante o mesmo período, o CNRS começou a instar seu pessoal para envolver-se com inovação e para abrir suas próprias firmas. $\mathrm{O}$ ambiente institucional mostrou-se favorável aos interesses empresariais de X. O pesquisador afirma que sua sólida reputação foi um incremento no começo de sua firma. Temendo não possuir as habilidades necessárias para gerenciar a firma, e desejando manter pleno envolvimento na pesquisa acadêmica, $X$ convidou um colega de laboratório, $\mathrm{V}$, para juntar-se a ele e dirigir a companhia - uma função que $\mathrm{V}$ ainda exerce. Hoje, X empenha-se cem por cento na pesquisa fundamental em biologia, mas mantém contato com a firma. Em certo período, ele participou da aventura empresarial, mas sem diminuir seus compromissos acadêmicos. Quando usa seu boné de empreendedor, X prepara amostras de teste, comercializa seus produtos e, em determinado ponto, fez até mesmo merchandise em supermercados - um panorama de atividades verdadeiramente de um homem de negócios! Entretanto, X insistiu plenamente sobre o ponto de que o negócio e o laboratório constituem duas esferas separadas, de modo que ele se recusou a misturá-las, pois considerava isso como uma configuração que seria prejudicial. Portanto, $\mathrm{X}$ alternou entre a universidade e o negócio sem subordinar um ao outro. Nessa trajetória de conhecimento comercial, a conexão de X com a instituição do CNRS provou ser particularmente crucial: graças a sua elevada posição na hierarquia de pesquisa e burocrática no GNRS, e graças à política favorável ao empreendedorismo, $\mathrm{X}$ não hesitou nem se constrangeu no que concerne à busca de seus interesses empresariais. Na verdade, deu-se o oposto.

Cientistas-empreendedores janus incorporam-se inteiramente na universidade, e intermitentemente incorporam-se da mesma maneira nos negócios. Suas capacidades cognitivas na pesquisa fundamental não diminuem em virtude das questões empresariais. Os negócios possuem uma lógica independente e suas próprias recompensas, o que não significa dizer que não existe convergência entre os dois domínios. Sugerimos que, tendo em vista a continuada liderança na produção de pesquisa fundamental, bem como a profunda inserção de janus na empresa, essa categoria, mais do que qualquer outra, é altamente capaz de disseminar aprendizagem acadêmica avançada e bem adaptada na empresa. O cientista-empreendedor janus pode, na verdade, constituir um caminho privilegiado para a geração de aprendizagem comercial - um caminho onde a ciência conserva sua autonomia relativa, os negócios mantêm sua lógica, e tal configuração gera sinergia ótima. Em muitos pontos os conhecimentos comerciais veiculados pelos cientistas-empreendedores janus superam tanto os dos acadêmicos quanto os dos pioneiros. Na verdade, a categoria janus representa um perfil promissor no que diz respeito a uma passagem equilibrada e efetiva entre esses campos de comunicação e ação. 


\section{Considerações finais}

O aumento da atenção dispensada às dinâmicas do conhecimento comercial é freqüentemente acompanhado por dois corolários importantes: primeiro, que as fronteiras entre a academia e a empresa devem diminuir ou até extinguir-se de maneira a permitir um desenvolvimento otimizado do conhecimento comercial através da transferência de informação exógena e, segundo, que o conhecimento comercial deve predominar sobre a aprendizagem acadêmica. O pensamento pós-moderno clama por uma inversão das alegadas relações hierárquicas tradicionais entre a ciência e as empresas de base tecnológica. Este artigo mostra que, para os cientistas ocupados com o empreendedorismo, as interações entre a universidade e a empresa são muitas vezes altamente complexas, e que os cientistas-empreendedores têm desenvolvido padrões de comportamento e modos de coordenação que freqüentemente desqualificam os pronunciamentos extremistas e sem nuances de alguns observadores desse fenômeno. Existem múltiplos caminhos na produção e aplicação do conhecimento comercial. Dois dos três caminhos aqui explorados demonstram que o máximo de sinergia e o mínimo de tensão entre o campo científico e a empresa acontecem numa configuração em que a autonomia relativa do campo científico é elevada - o caso dos grupos denominados acadêmicos e janus. No caso dessas duas categorias, a presença de autonomia e destarte a existência de fronteiras não impedem proveitosas incursões recíprocas. Havendo autonomia relativa do campo científico, deixam-se livres possibilidades de infiltração e passagens através das fronteiras. A comunidade chamada de pioneiros, a que mais fortemente se identifica com a indústria, é a menos preocupada com o campo científico e sua autonomia, e exibe uma sinergia apenas modesta e uma tensão aguda. A forte incorporação de valores empreendedores é acompanhada por um distanciamento voluntário em relação à academia, o que contrasta com o janus, constituído tanto pelo compromisso com a universidade como com a indústria, só que respeitando períodos de tempo alternados. O grupo janus coordena segmentos de tempo ao invés de formas de prática, e é esse modo de coordenação seqüencial que faz com que tal comunidade se apresente como a mais eficiente fornecedora de conhecimento comercial em nossa população. Autonomia e incursões seletivas intermitentes entre as fronteiras são, portanto, positivamente correlacionadas com a aprendizagem comercial, enquanto a negligência de autonomia e conseqüente indiferença às divisões de trabalho e dinâmicas das fronteiras correlacionam-se negativamente com a sinergia entre universidadeempresa e com a produção e a difusão, incessante e de ponta, do conhecimento comercial. Finalmente, sugerimos que a permanência de diversos caminhos de aprendizagem comercial, cada qual conectado a um modo específico de coordenação, pode consubstanciar e enriquecer o entendimento da perspectiva de tripla hélice (cf. Etkowitz \& 
Leydesdorff, 2000) que enfatiza a coexistência de novos arranjos cognitivos e organizacionais, e que define historicamente o novo lugar desses arranjos dentro das configurações prévias.

Traduzido do original em inglês por Renato Rodrigues Kinouchi

\author{
Terry SHINN \\ Pesquisador do GEMAS (UMR 8598), \\ Maison des Sciences de l'Homme de Paris, França. \\ shinn@msh-paris.fr \\ Erwan LAmY \\ Pesquisador do IDHE Cachan (UMR 8533), \\ Professor da Université Paris 7-Denis Diderot, França. \\ lamy@idhe.ens-cachan.fr
}

\begin{abstract}
This article examines paths of commercial learning, where the environment is perceived as multi referent and pluralistic. The informationally rich category of scientist-entrepreneurs constitutes our research terrain. This group represents the acme of strong science and enterprise interaction. Data from a written questionnaire and extensive oral interviews of 41 people and information from four laboratory-enterprise micro-studies, form the base of our description and conclusions. Three paths of commercial knowledge emerge - one associated with a group labeled "academics", another connected to an ensemble dubbed "pioneers" and still another path linked to a cohort christened "janus". These groups diverge in terms of four factors: degrees of university-enterprise synergy; degrees of university-business tension; degrees of relative autonomy of the scientific field; the presence of a particular mode of university-enterprise coordination. We speculate that certain paths prove more stable and effective than others in the generation and diffusion of commercial knowledge. Our discovery of multiple paths within the commercial knowledge process, occurring in a multi referent, pluralistic environment, challenges the radical contextualization of science mode 2 message which purports a significant lowering of the boundaries between science and industry and society, or even the demise of said differentiations and boundaries.
\end{abstract}

KEYwords • Commercial knowledge. Multi referent. Pluralistic environment. University-enterprise synergy. Synergy index. Relative autonomy. Modes of coordination. Boundary crossing. 


\section{REFERÊNGIAS BIBLIOGRÁFIGAS}

Alter, N. (Ed.). Les logique de l'innovation. Paris: La découverte, 2002.

Bourdieu, P. Science de la science et réflexivité. Paris: Raisons d'agir, 2001.

Cassier, M. L'engagement des chercheurs vis à vis de l'industrie et du marché. In: Alter, N. (Ed.). Les logique de l'innovation. Paris: La découverte, 2002. p. 155-82.

Cinrs. Disponível em: <http://hydre.auteuil.cnrs-dir.fr/dae/faitsetchiffres20o3/o9_partenariats.html〉. Acesso em: jan. 2005.

ELIAs, N. et al. Scientific establishements and hierarchies. Dordrecht: Reidel, 1982.

Eтzкоwттz, H. The norms of entrepreneurial science: cognitive effects of the new university-industry linkages. Research Policy, 27, 8, p. 823-33, 1998.

Etzkowitz, H. \& Leydesdorff, L. The dynamics of innovation: from national systems and "Mode 2 " to a triple helix of university-industry-government relations. Research Policy, 29, 2, p. 109-23, 2000.

Etzkowitz, H.; Webster, G.; Gebhardt, B. \& Terra, R. C. The futures of the university and the university of the future: evolution of ivory tower to entrepreneurial paradigm. Research Policy, 29, 2, p. 313-3o, 2000.

Fiset, L.; Ippersiel, M.-P.; Martineau, Y. \& Trépanier, M. Institutions du savoir et PME: synthèse des écrits et bilan des problèmes et besoins des intervenants québécois. INRS-Urbanisation, 1999. Disponível em: $<$ www.ucs.inrs.ca/default.asp?p=marti . Acesso em: 20 out. 2005 .

Freidson, E. P. Professionalism reborn: theory, prophesy and policy. Chicago: University of Chicago Press, 1994.

. Professionalism, the third logic: on the practice of knowledge. Chicago: University of Chicago Press, 2001.

Giввоns, A. S. et al. Effects of administering feedback following extended problem solving. Journal of Educational Computing Research, 25, 4, p. 417-26, 2001.

Gibbons, M.; Limoges, G.; Nowotny, H.; Schwartzman, S; Scott, P. \& Trow, M. The new production of knowledge: the dynamics of science and research in contemporary societies. London: Sage Publications, 1994 .

Godin, B. \& Gingras, Y. The place of universities in the system of knowledge production. Research Policy, 29,2, p. $27^{3-78,2000 .}$

Grossetti, M. Science, industrie et territoire. Toulouse: Presses Universitaries du Mirail, 1995.

Joerges, B. \& Shinn, T. Instrumentation, between science, state and industry. Dordrecht: Kluwer Academic Publishers, 2001.

KornhaUser, W. Scientists in industry: conflict and accommodation. Berkeley: University of California Press, 1962.

Krimsky, S. Science in the private interest: has the lure of profits corrupted biomedical research? Lanham: Rowman and Littlefield Publishers, 2003.

LAMY, E. La fragmentation de la science à l'épreuve des start-ups: retour critique surun constructivisme social au travers de l'étude des modes de coordination des pratiques scientifiques et marchandes lors des projets de création d'enterprise par des chercheurs du sector public. Paris, 2005. These (Doctorat d'épistemologie). Université Paris 7 - Denis Diderot.

Merton, R. K. The normative structure of science. In: Merton, R. K. (Ed.). The sociology of science: theoretical and empirical investigations. Chicago: University of Chicago Press, 1973 [1942].

Merton, R. K. (Ed.). The sociology of science: theoretical and empirical investigations. Chicago: University of Chicago Press, 1973 [1942].

MustaR, B. Spin-offs from public research: trends and outlook. STI Review, 26, p. 165-72, 2001. 
Mustar, B. Gréation d'enterprises à partir de la recherche. In: Mustar, P. \& Penan, H. (Ed.). Encyclopedie de l'innovation. Paris: Economica, 2003.

Mustar, P. \& Penan, H. (Ed.). Encyclopedie de l'innovation. Paris: Economica, 2003.

Nowotny, Н.; Sсотт, H. P. \& Giвbons, M. Re-thinking science: knowledge and the public in an age of uncertainty. Cambridge, UK: Polity Press, 2001.

OwEN-SMIth, J. From separate systems to a hybrid order: accumulative advantage across public and private science at research on universities. Research Policy, 32, 6, p. 1081-104, 2003.

Ramunni, G. Les sciences pour l'ingénieur: histoire du rendez-vous des sciences et de la société. Paris: CNRS Éditions, 1995 .

Reamer, A.; Igerman, L. \& Youtie, J. Technology transfer and commercialization: their role in economic development. Washington, DC: US Economic Development Administration, 2003.

Shinn, T. Scientific disciplines and organizational specifies: the social and cognitive configuration of laboratory activities. In: Elias, N. et al. Scientific establishements and hierarchies. Dordrecht: Reidel, 1982. p. 239-64.

Shinn, T. \& Ragouet, P. Controverses sur la science: pour une sociologie transversaliste de l'activité scientifique. Paris: Raisons d'agir, 2005.

Slaughter, S. \& Leslie, L. Academic capitalism: politics, policies, and the entrepreneurial university. Baltimore: Johns Hopkins University Press, 1997.

STI REVIEw. Special Issue on Fostering high-tech spin-offs: a public strategy for innovation. OCDE, 26, 2001.

VAvakova, B. La science de la nation: les paradoxes politiques de la logique économique. Paris: L'Harmattan, 2001.

Whitley, R. The intellectual and social organization of the sciences. Oxford: Clarendon Press, 1984.

Ziman, J. Reliable knowledge: an exploration of the grounds for belief in science. Cambridge: Cambridge University Press, $197^{8 .}$ 